\title{
Australia: getting there
}

\author{
Alcuin Wilkie
}

There have been two recent accounts in the Psychiatric Bulletin (Harrison, 1989; Kisely, 1993) which have given some practical advice about getting work in Australia. They did, however, rather gloss over the details. With clear memories of the difficulties of arranging a one year training post in Sydney, New South Wales (NSW) and having been approached by numerous mainly junior colleagues asking about details of arranging a similar trip, I am writing what I hope will be a useful and accurate "Getting your Australian visa and medical registration made easy" guide.

Finding work as a psychiatry trainee or indeed as a fully fledged psychiatrist in Australia is by no means easy, unless you are a graduate of an Australian or New Zealand medical school and an Australian citizen or eligible for Australian residency. There are three separate but interdependent conditions that all have to be fulfilled in order to work in Australia: finding a post, getting a visa and getting medical registration.

\section{Finding a post}

There is a general sympathy towards British and Irish graduates in the Australian medical system, indeed when I left my post in Australia I was exhorted by my boss to "keep sending us psychiatrists". Furthermore there is no lack of psychiatrists in the public health system who would be most happy to have a British trainee working for them. However they are not going to offer a post to someone unless they are fairly sure that person will fulfil the visa and registration requirements.

As more than $90 \%$ of the population live in the major cities of Australia's coastal strip, virtually all of psychiatry training takes place in these areas and this is where I recommend looking for a post. Predictably the best opportunities depend on contacts and word of mouth. Essentially it is a question of either arranging a work exchange with an Australian trainee (as I did) or finding a hospital consultant (known in Australia as a 'staff specialist') or clinical director who is prepared to organise a personalised training programme for a British trainee, which will satisfy medical registration and immigration conditions. A third possible way in is to find a teaching and/or research post and a supervisor to sponsor your application.

If you do not know of a possible post or do not have any contacts then the best ways of looking for posts are to write, expressing interest, to the professors of psychiatry in Australia's medical schools and to write to clinical directors of psychiatry whose names and addresses can be found in the Medical Directory of Australia (Arnold, 1995).

\section{Immigration}

Assuming you have found a prospective post and supervisor, the next hurdle is arranging your visa. This can take from a few weeks (about five in my case) to six months, depending on how you go about it. You begin by making a visa application, with the appropriate fee and three identical passport photographs to the Australian High Commission in London or the Consulates in Manchester and Edinburgh. This is done on Form 147 - a number which by the end of the whole process will be firmly engraved on your memory. Meanwhile your supervisor in Australia informs the medical administration department in the hospital where you will be working of your proposed arrival.

They in their turn submit an application to the Department of Immigration, Local Government and Ethnic Affairs (DILGEA) in Canberra, who if they approve it then inform the Australian immigration department in Britain, who will then grant you a visa provided they have not found some inadequacy in your Form 147 (which invariably they do). Then, depending on your length of stay you may be obliged to submit to a chest X-ray and a medical, both of which have to be performed by practitioners approved by the immigration authoritles, and, of course, at your own expense. On returning your favourable medical report in a sealed, tamper-proof envelope, everything is once again scrutinised. Then, the last minute panic - in my case the realisation by immigration that there was no physical proof that there was anyone coming to London to exchange jobs with me. A telephone call and a quick fax later and the immigration officers were satisfied. The Strand has never looked so bright and sunny to me as it did the day I walked out of Australia House with a 'temporary residence visa 
class 411 - exchange' stuck neatly on page 13 of my passport.

It is advantageous to be on an exchange and get an exchange visa which is free rather than an occupational training visa (class 442) for which you have to pay (see below under 'Expenses').

Whether this whole process takes six weeks or six months depends on: first, the degree of pressure by telephone and fax you bring to bear on the medical administration of your host institution in Australia; and second, the degree to which you are able to personally attend and telephone, rather than correspond with, the appropriate Australian High Commission or Consulate.

\section{Medical registration}

Of all the hurdles this is probably the most difficult to negotiate as medical registration in Australia has recently undergone some very important changes. Prior to January 1993 basic medical qualifications of UK and Irish medical schools were recognised for full medical registration in all Australian states and territories, with the exception of NSW and Victoria. However there was no recognition between states and territories of each other's medical registration conditions. From January 1993, as a result of agreement between Commonwealth and State governments, standardised medical registration conditions have been introduced across all states and territories, essentially advantageous for Australian doctors, allowing them to work in any state or territory, but more restricting on medical registration in Australia of UK and Irish graduates. There are now two forms of registration: with, and without conditions. For both categories the candidate must have "an adequate command of English for the practice of medicine, be of good fame and character and have the physical and mental competence to practice medicine". Unconditional registration is only available to Australian and New Zealand medical school graduates, who have completed their intern training period, and to overseas medical graduates who have passed the Australian Medical Council (AMC) exam - equivalent to the General Medical Council's Professional and Linguistic Assessment Board (PLAB) exam. Registration with conditions (RWC) is now the main route for British graduates who want a taste of medical practice in Australia. The following categories of registration with conditions are of relevance: 1) 'Postgraduate training' for those 'seeking to undertake a period of structured postgraduate training in Australia'; 2) 'Public interest/areas of need': this category enables Medical Boards to register applicants to work in specialities and locations that are not popular in Australia, generally in country areas; 3) Teaching or research', where the applicant "can satisfy a Board that their qualifications and experience are appropriate for this category of registration"; and 4) 'Overseas trained specialist' which allows overseas trained specialists the opportunity to practise independently "subject to being assessed to the satisfaction of the relevant Specialist College and certified by the AMC".

This means that it is still possible for psychiatrists of consultant status in the UK to work in Australia without taking the AMC examination or having the Fellowship of the Royal Australian and New Zealand College of Psychiatrists (FRANZCP); the details of this procedure are available from the AMC. In my case an initial application for approval for medical registration was submitted to the Medical Board by the Medical Administration in my host hospital, and I was informed that on arrival I would have to present myself to the NSW Medical Board (GMC equivalent) with: the original or a certified copy of my medical degree; my GMC registration certificate; a GMC certificate of good standing: my passport and visa; two passport photographs; two character references no more than two years old; a supervisory declaration from my posting and a supervisory declaration from my host institution. What I was not informed of was that I would also have to bring with me a cheque for $\$$ \$275. Shortly after arrival in Sydney, I presented with the above documentation which was all taken behind closed doors. I was then required to sign a declaration that I would return to England at the end of my training period and that I would not take the AMC examination. I then had to wait for the next NSW Medical Board Meeting (they occur every 2 weeks) before I was granted registration and could see patients. The terms of my registration were restrictive, specifying my supervisor and hospital and disallowing me from working outside my nominated hospital, including locum work.

\section{Will my partner be able to get work?}

If a person has obtained a temporary resident's visa with permission to work, then their partner would be eligible for an 'interdependency visa' which will allow them to live and work in Australia during the same time frame. If you are married to your partner this simplifies the bureaucracy. If you are in a common-law or as the Australians call it 'de facto' relationship, then you will be required to prove the status of the relationship to the satisfaction of the authorities. Same gender partnerships are treated identically to opposite gender partnerships for the purpose of applications for permanent residency but they are not currently eligible for an 'interdependency visa' which will allow them 
to live and work in Australia, and they are obliged to apply for a temporary residence visa in their own right.

\section{Practicalities}

Travel

The cheapest months to fly are February to July and it is worth considering a round the world ticket' which will allow visits to other destinations en route. It is cheaper to buy a return ticket rather than two singles but the latter option allows you to change your plans more easily. It is worthwhile considering flying via the United States rather than Asia as the flights usually give you a much larger luggage allowance (two items of luggage totalling not more than $60 \mathrm{~kg}$ versus $25 \mathrm{~kg}$ per person).

\section{Accommodation}

Rental accommodation in Australia is generally unfurnished, although there are specialised furniture rental outlets. Hospital accommodation is usually basically furnished and can be easily arranged from abroad first.

\section{Shipping}

The benefits of shipping various items probably outweigh the costs both in monetary and emotional terms - during periods of home sickness it is comforting to have a few transitional objects to hand - in our case: some favourite books and compact discs; cooking knives and chopping board and two saucepans. Shipping takes 8-12 weeks door to door.

\section{Transport}

In Australia, more than anywhere, $a$ man is not a man with a ticket in his hand. Cities in Australia sprawl much more than British cities and unless you live centrally, travel without a car can be frustrating and time consuming. Second hand cars in Australia initially seem more expenstve than UK cars of the same age, but represent better value as rust is not a serious problem in Australia. If you have evidence of a no claims bonus, take it with you.

\section{Finances (see also Table 1)}

It will take a few days to sort out a bank account in Australia. Take a money draft with you. If on an
Table 1. Expenses: typical list of expenses

\begin{tabular}{lr}
\hline Hem & Price $(S)$ \\
\hline Retum air fare (each) & $\$ 1000.00$ \\
Shipping effects both ways & 300.00 \\
Visa & 55.00 \\
Medical examination & 50.00 \\
Chest X-ray and report & 20.00 \\
GMC certificate of good standing & 40.00 \\
Medical registration in Australia & 140.00 \\
Forwarding mail & 60.00 \\
& $\$ 1665.00$ \\
\hline
\end{tabular}

exchange it may be possible to arrange to continue receiving your income in the UK. If out of the UK for 12 months you should be eligible for a nil tax code (contact your tax office). Using UKbased credit cards is a very convenient way of accessing UK funds if you do not have a large income in Australia. The cost of living in Australia is significantly less than in the UK but salaries are correspondingly lower.

\section{Health}

British citizens are entitled to Australian 'Medicare' benefits under a reciprocal agreement. This covers 'necessary treatment' but excludes most elective procedures. It may be necessary to take out insurance to cover the cost of ambulance trips.

\section{Further reading}

Medical Employment in Australia, compiled by the Australian Medical Association, available from the International Department of the British Medical Association, London: this gives a variety of useful information and addresses.

\section{References}

ARNold, P. C. (ed) (1995) Medical Directory of Australia Australia: Australian Medical Publishing.

HARRISON, J. (1989) An Australian exchange. Psychiatric Bulletin, 13, 361-362.

KISELY, S. (1993) Training. manpower and employment in Australia. Psychiatric Bulletin, 17, 669-671.

Alcuin Wilkie, Senior Registrar, Community Mental Health Unit, St Charles Hospital, Exmoor Street, London W10 6DZ 